\title{
COMPARISON OF THE PERFORMANCE OF REFRIGERATION SYSTEMS WITH AND WITHOUT NANOPARTICLES
}

\author{
HICHAM MACHMOUCHI \& RAVISHANKAR PILLAI \\ School of Engineering, Emirates Aviation University, UAE
}

\begin{abstract}
In order to achieve better enhancement, reliability and efficiency of refrigeration and air conditioning systems, researchers have effectively utilized the application of nanoparticles in cooling systems due to higher heat transfer and thermo-physical capabilities. Conventional refrigerants are considered as one of the factors that contribute to global warming potential (GWP) and ozone depletion potential (ODP) resulting in global warming. Many research organizations recommend the utilization of the application of nano refrigerants in refrigeration systems. In this paper, a study on vapor compression refrigeration system with nanoparticles mixed with R134a refrigerant is conducted, the coefficient of the performance and refrigeration effects of the system are determined from the existing observations without the addition of nanoparticles. Aluminum oxide, zinc oxide, titanium oxide and copper oxide nanoparticles are considered and utilized here to calculate coefficient of performance (COP) and refrigeration effects. Nanoparticles that depict higher COP result in energy savings. On the other hand, nanoparticles that depict lower COP, result in higher consumption of power. The resulting performance of the system showed apparent improvement by replacing conventional refrigerants with nano refrigerants. It is therefore, concluded that the COP of refrigeration system with added nano additives in refrigerant fluid is higher than that of systems running with pure refrigerant fluid. In addition, the energy of the refrigeration systems is reduced due to the addition of nanoparticles in refrigerant fluid. Around 38\% increase in COP was recorded in this study. Moreover, $\mathrm{CuO}$ nanoparticles showed high value of COP when blended with R134a compared to other nanoparticles. COP of the refrigeration systems vary with the type of refrigerants used in the system.
\end{abstract}

Keywords: vapor compression refrigeration, nanoparticles, nano refrigerant, ozone depletion potential, surface temperature.

\section{INTRODUCTION}

Nanotechnology is the study and analysis of matter at the scale of up to $100 \mathrm{~nm}$. Most of the refrigeration and air conditioning systems suffer from poor performance due to poor properties of heat transfer characteristics. Earlier, most of the applications of nano solid particles have been affected by some challenges, such as settling of solid particles at the bottom of the enclosure or agglomeration of particles.

Various experiments conducted by research organizations have shown that dispersion of nanoparticles or mixing nanoparticles with conventional refrigerant would increase the heat transfer characteristics by creating proper dispersion of nanoparticles. Nanofluids are developed by the addition of nanoparticles into base fluids like water resulting in higher thermal conductivity than the base fluids. Better heat transfer capability of nanofluid, Brownian motion of scattering ability, and better stability are some of the major factors that lead to making nanofluids superior to the base fluids. To obtain better heat transfer characteristics, require less pumping power compared to the base fluids in refrigeration system. The surface area per unit volume is more in nanoparticles compared to other solid particles making it suitable for enhancing the thermal conductivity for the better development of refrigeration systems. 
There have been many environmental impacts that have smitten refrigeration system. Ozone depletion potential and global warming potential have been the major environmental effects due to the deposition of human made chemical into atmosphere and absorption of IR radiation from the surface of earth leading to increase in earth surface temperature.

At present time, there is wide range of nanoparticles available. They come in different material, shape and size. They are available in metal oxide ceramics such as Al, Zn, Ti and other oxides of iron and remaining particles exist in pure metal like $\mathrm{Au}, \mathrm{Ag}$ and $\mathrm{Cu}$.

Nanoparticles of size ranging from 10-100 nm, are mixed with base fluids such as water with $0.05-1 \%$ nanoparticles concentration. Improvement in thermal conductivity can be observed compared to the base fluids. This is due to following factors:

1. Nanofluid reduces clogging of particles.

2. High surface area yields nanofluid with high heat transfer rate between the fluids and solid particles.

3. Dispersion of nanoparticles can be increased.

Nanoparticles are made from ceramics, split into metal oxides of iron, Aluminum, Zinc and Silicate particles. These are in the form of nano scale flakes of clay. It has been found in previous studies that mixing of nanoparticles with refrigerant would improve the thermophysical properties and heat transfer characteristics, thus enhancing the performance of refrigeration system.

When metallic or nonmetallic nanoparticles or nanofibers, nano rods, nano tubes and nano wires of solid in nature are mixed with base fluids, nanofluids are formed. Nanoparticles have the ability to react with liquids at molecular level due their size $(<100 \mathrm{~nm})$, resulting in conduction of heat compared to other heat transferring liquids.

Due to the conduction and convection capabilities, nanofluid prove to have enhanced and better heat transfer coefficient. In order to achieve better thermo-physical properties, such as thermal diffusivity, viscosity, thermal conductivity and heat transfer coefficients, metallic nanofluids are used widely. They possess all the above mentioned properties which are better compared to water and oil considered as the base fluids. In this investigation, four main nanoparticles are used namely $\mathrm{Al}_{2} \mathrm{O}_{3}, \mathrm{ZnO}, \mathrm{TiO}_{2}$ and $\mathrm{CuO}$. These nanoparticles are allowed to disperse in $\mathrm{R} 134 \mathrm{a}$ type refrigerant.

It has been concluded that, nanofluids face many challenges such as variation in thermal conductivity, Brownian motion of particles and their characteristics. Some of the other challenges are very low specific heat compared to base fluids, higher concentration of nanoparticles leads to rise in viscosity, complex production processes and high operating costs. To prevent any deposition of particles, the stability of nanoparticles dispersion must be taken into consideration.

\section{OBJECTIVE}

The applications of nanofluids can be seen in Industrial cooling systems, nanofluid coolant and nanofluid fuel in automobiles, geothermal power plant and nuclear reactors. Nanotechnology helps the modern world to achieve clean and sustainable environment by eliminating environmental hazardous energy. According to the studies, metal nanoparticles [1], [2] are most widely used in the industries. The applications of nanoparticles are considered as safe due to the interaction between the particles and liquids. Liquid phase of metal and metal oxide nanoparticles is vital, as it is through the liquid phase where materials come in contact with living systems. Properties of Aluminum Oxide are tabulated in Table 1. 
Table 1: Aluminum oxide properties [2].

\begin{tabular}{|l|l|}
\hline General formula & $\mathbf{A l}_{\mathbf{2}} \mathbf{O}_{\mathbf{3}}$ \\
\hline Density & $1.06 \mathrm{~g} / \mathrm{cm}^{3}$ \\
\hline Size & $25-30 \mathrm{~nm}$ \\
\hline Structure & Cubic \\
\hline Molecular weight & 101.90 \\
\hline Color & White \\
\hline
\end{tabular}

Properties of zinc oxide are depicted in Table 2.

Table 2: $\mathrm{ZnO}$ properties [3].

\begin{tabular}{|l|l|}
\hline General name & Zinc oxide \\
\hline Formula & $\mathrm{ZnO}$ \\
\hline Density & $5.6 \mathrm{~g} / \mathrm{cm}^{3}$ \\
\hline Size & $30 \mathrm{~nm}$ \\
\hline
\end{tabular}

The general properties of $\mathrm{CuO}$ nanoparticles are tabulated in Table 3.

Table 3: $\mathrm{CuO}$ properties [4].

\begin{tabular}{|l|l|}
\hline General name & Copper oxide \\
\hline Formula & $\mathrm{CuO}$ \\
\hline Density & $6.3 \mathrm{~g} / \mathrm{cm}^{3}$ \\
\hline Size & $30-50 \mathrm{~nm}$ \\
\hline
\end{tabular}

3 VAPOR COMPRESSION REFRIGERATION SYSTEM

The most cost efficient and simple construction of cooling device in existence is vapor compression refrigeration (VCR) systems. Industrial sectors such as petroleum refineries, petrochemical factories, food processing companies and natural gas plants utilize the application of VCR systems to cool required spaces by removing existing heat [5]. VCR systems work on the reverse of Carnot cycle, where the heat is transferred from cold reservoir to a hot one. To achieve cooling effect, the device undergoes compression and expansion stages by means of mechanical energy. Conventional VCR systems use Ammonia as the basic refrigerant in changing phase from liquid to gas and vice versa [6]. Refrigerant, which has been considered as the working fluid for the device, enters the system and experiences a change of state from liquid to gas and vice versa. When the device is prone to any leakages, the highly toxic Ammonia gives unpleasant odor, which is one of the major drawbacks. This prompted the development of Freon $\left(\mathrm{CCl}_{2} \mathrm{~F}_{2}\right)$, an alternative, odorless, refrigerant that replaced Ammonia.

\subsection{VCR system operation}

The major components that drive VCR systems efficiently are evaporator, compressor, condenser and expansion valves. A schematic of a simple VCR system is depicted in Fig. 1.

With reference to Fig. 1, a VCR system undergoes multiple phases from phase 1 to phase 2 as follows: 


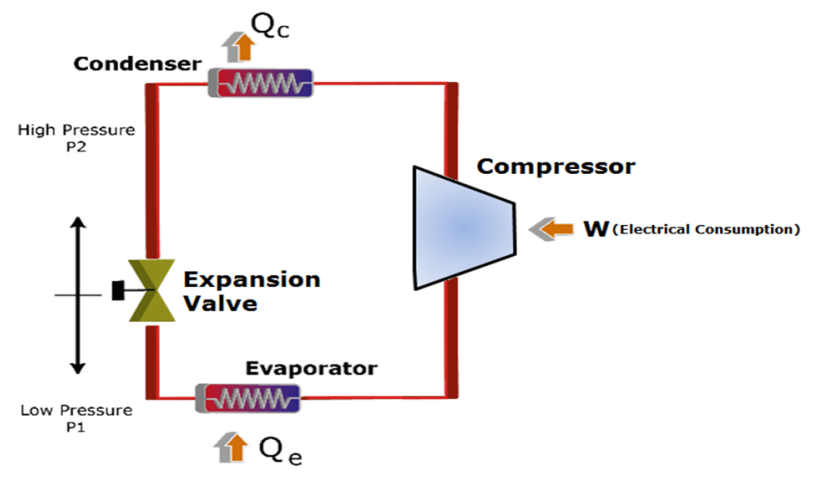

Figure 1: Vapor compression refrigeration system diagram [3].

Phase 1. Compressor: The main component of the device that drives the entire system efficiently. Compressor used in this device can be of centrifugal, reciprocating or rotary type. There are usually two pressures acting in refrigeration system, namely, low pressure and high pressure. Low pressure or evaporator pressure is regulated by the expansion device, whereas the high pressure or condenser pressure is regulated by the compressor. The pipeline that connects from the evaporator outlet to compressor inlet is called "Suction line" and the pipeline connecting from the compressor outlet to condenser inlet is termed "Discharge line". A power source is used to run the compressor.

Phase 2. Condenser (Heat exchanger): In this stage the refrigerant at high temperature and pressure enters the condenser through the discharge line from compressor outlet. The cooling process in condenser is attained in three ways. At first, the vapor refrigerant from compressor at superheated state is de-superheated. Secondly, the vapor refrigerant changes its state to liquid refrigerant and finally, the liquid refrigerant is sub-cooled.

Phase 3. Throttling Valve (Expansion): In this stage, refrigerant in liquid phase at high pressure enters the throttle valve through a filter, where any foreign particles can be removed. These filters also contain a silica gel to absorb any moisture content. In this valve, expansion takes place lowering the pressure of refrigerant.

Phase 4. Evaporator: At this stage, the liquid refrigerant at low temperature and pressure enters the evaporator inlet from the expansion valve outlet and the phase change from liquid to vapor takes place. The vapor refrigerant formed in the evaporator absorbs heat from the space or surroundings to be cooled and the vapor refrigerant enters the compressor inlet at low temperature and pressure and begins the next cycle.

\subsection{R134a refrigerants}

Refrigerant R134a can also be termed as 1,1,1,2-Tetrafluroethane under hydro fluoro carbon (HFC) refrigerants. CF3CH2F is the chemical formula of R134a. Hydro fluoro carbon, a fluorinated refrigerant, has been considered as the green refrigerant. HFC refrigerants are known as the alternative refrigerants to HCFC (hydrogen chloro fluoro carbon) and CFC (chloro fluoro carbon) refrigerants because HCFC's and CFC's are considered as global warming potential (GWP) and ozone depletion potential (ODP). R134a refrigerants are extensively used in air conditioning units as well as refrigeration units in industries for cooling purposes. R23, R32, R134a, R404a, R407a, R407c, and R410a are some of the refrigerants that fall under the category of HFC refrigerants [7]. 
R134a refrigerant is resistant to corrosion, intoxic in nature and inflammable. Today, the application of R134a can be seen in air conditioning systems within automobile industries. But, it has been known that lubricants are not compatible with R134a refrigerant.

Table 4 shows selected important parameters of R134a refrigerant.

Table 4: R134a properties [3].

\begin{tabular}{|l|l|}
\hline Parameters & R134a \\
\hline Global warming potential $(\mathrm{GWP})$ & 1430 \\
\hline Boiling point & $-26^{\circ} \mathrm{C}$ \\
\hline Critical temperature & $122^{\circ} \mathrm{C}$ \\
\hline Ignition temperature & $700^{\circ} \mathrm{C}$ \\
\hline Solubility & $0.1 \%$ soluble in weight at $25^{\circ} \mathrm{C}$ \\
\hline
\end{tabular}

Many research organizations have conducted various experiments to resolve the issues of ozone depletion and global warming due to the usage of conventional refrigerants in domestic refrigerators. Available experimental data have shown that, nano refrigerants are best suited to replace conventional refrigerants. Nanoparticles like $\mathrm{Al}_{2} \mathrm{O}_{3}, \mathrm{CuO}, \mathrm{TiO}_{2}$ and $\mathrm{ZnO}$ with particle size ranging from 40 to $50 \mathrm{~nm}$ and $0.5 \%$ to $1 \%$ were mixed with different refrigerants such as R134a, R600a, and R12a. The important parameters such as evaporator temperature, coefficient of performance (COP), vapor pressure, freezing capacity, discharge temperature and pressure and energy consumption were measured.

Due to better energy performances and environmental conditions, R134a has been considered as the working fluid in this paper since it is the most widely used over other working fluids. This is based on the fact that the thermophysical properties of these nanoparticles are influenced due to the stability in the nanoparticles dispersion. If nano refrigerants are applied in the refrigeration system, the whole system should be stable at any temperatures and pressures as the variations of these two parameters occur due to the flow of refrigerant through multiple components of the refrigeration system. Without any sort of deposition at the base, phase change and clustering, and dispersion of nanoparticles will remain unchanged for certain period of time. Variations in thermophysical properties are found due to the preparation techniques of the nanofluid. In addition, many properties including thermal conductivity are dependent on the rate at which the particles are agitated.

Islam et al. [8] presented a research paper on $\mathrm{Al}_{2} \mathrm{O}_{3}-\mathrm{R} 141 \mathrm{a}$ experiment at $0.5 \%$ to $2 \%$ of nano concentrations. At $2 \%$ volume concentration, the viscosity and thermal conductivity of nano refrigerant improved effectively compared to pure R141a refrigerant. In another paper, $\mathrm{TiO}_{2}-\mathrm{R} 123 \mathrm{a}$ experiment was conducted in domestic refrigerator by considering nano concentrations of $1 \%$ and $2 \%$. From the results he concluded that when the volume of concentration of nanoparticles is high, both viscosity and heat transfer coefficient increases thus improving the performance of system with higher COP.

Table 5 shows some of the selected experiments on VCR system considering nano refrigerants as the refrigerant medium.

\section{METHODOLOGY}

\subsection{Nanofluids preparation [9]}

Nanofluids are prepared by the complete dispersion of nanoparticles into base fluids like water, oil, ethylene glycol etc. In order to achieve proper dispersion between base fluids and 
Table 5: Selected experiments conducted by research organizations.

\begin{tabular}{|l|l|l|l|}
\hline Author & $\begin{array}{l}\text { Experiment } \\
\text { type }\end{array}$ & $\begin{array}{l}\text { Nano refrigerant } \\
\text { type }\end{array}$ & Results \\
\hline $\begin{array}{l}\text { Ajayi et } \\
\text { al. }[14]\end{array}$ & $\begin{array}{l}\text { Investigations } \\
\text { on nano- } \\
\text { particles in } \\
\text { VCRS }\end{array}$ & $\begin{array}{l}\mathrm{R} 134 \mathrm{a}-\mathrm{Cu} \text { and } \\
\mathrm{R} 600 \mathrm{a}-\mathrm{Cu} \text { mixtures }\end{array}$ & $\begin{array}{l}\text { The results show that } \mathrm{Cu} \text { when } \\
\text { mixed with R600a and } \mathrm{R} 134 \mathrm{a} \\
\text { have higher heat transfer } \\
\text { characteristics than pure R134a. }\end{array}$ \\
\hline Ghorbani & $\begin{array}{l}\text { Nano } \\
\text { refrigerant } \\
\text { et al. }[15]\end{array}$ & $\mathrm{CuO}-\mathrm{R} 134 \mathrm{a}$ mixture & $\begin{array}{l}\text { The system performance } \\
\text { increases by } 4 \%, 8 \% \text { and } 14 \% \text { for } \\
0.5 \%, 1 \% \text { and } 1.5 \% \text { of volume } \\
\text { concentrations. }\end{array}$ \\
\hline
\end{tabular}

nanoparticles, surfactants are added. Proper dispersion and stability of nanoparticles are some of the factors to be considered before the preparation of nanofluids.

Table 6 shows the thermal conductivity of R134a and selected nanoparticles.

Table 6: Thermal conductivity for various nanoparticles [9].

\begin{tabular}{|l|c|}
\hline Material & $\begin{array}{c}\text { Thermal conductivity } \\
(\mathbf{W} / \mathbf{m K})\end{array}$ \\
\hline R134a & 0.48 \\
\hline Aluminum oxide & 0.08 \\
\hline Zinc oxide & $10-50$ \\
\hline Copper oxide & $20-40$ \\
\hline Titanium oxide & $0.4-11.8$ \\
\hline
\end{tabular}

In this paper, aluminum oxide, copper oxide, zinc oxide and titanium oxide are used as nanoparticles, labolene, as surfactants and water, as base fluids. For the nanofluids preparation, following components are used:

- Magnetic stirrer

- Magnetic bead (stir bar)

- Beaker

Nanoparticles are mixed with base fluid and surfactant in a beaker. The beaker is then placed on a magnetic stirrer with a magnetic bead dispersed into the solution, for stirring purpose. The magnetic force from the beneath of the stirrer rotates the magnetic bead rapidly thus stirring the solution. Surfactants also play a major role in nanofluids preparation in order to ensure the stability of nanoparticles. The final solution is then transferred and collected in a container.

\subsection{Experimental calculations}

A p-h chart for calculating and analyzing refrigeration systems performance is used for measuring the refrigerant effect and COP. P-h diagram is made respectively for a specified refrigerant. In this paper $\mathrm{p}$-h chart of R134a refrigerant is depicted to study the refrigeration system performance.

Fig. 2 shows the p-h diagram for R134a refrigerant. 


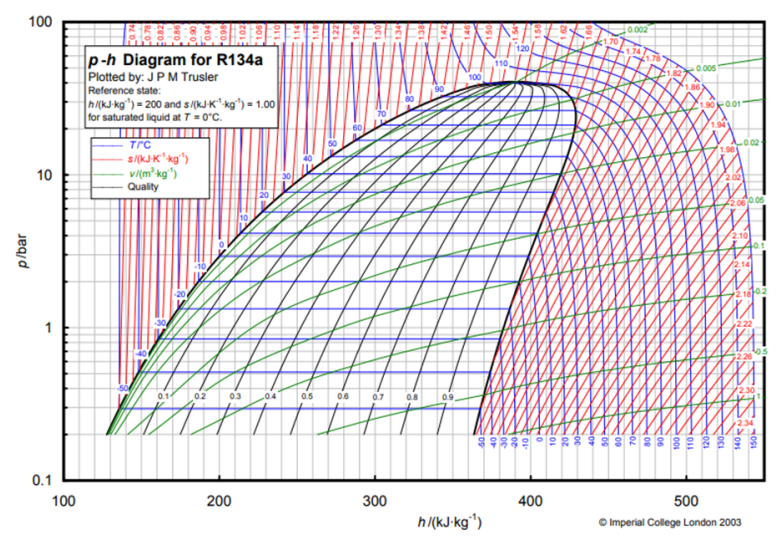

Figure 2: R134a p-h chart [10].

COP comparison with nano refrigerant system and pure refrigerant system. In the experiment, $\mathrm{R} 134 \mathrm{a}$ is mixed with $\mathrm{Al}_{2} \mathrm{O}_{3}, \mathrm{ZnO}, \mathrm{CuO}$ and $\mathrm{TiO}_{2}$ and the enthalpy values are found from $\mathrm{p}-\mathrm{h}$ chart of R134a, for calculating refrigeration effect (RE) and COP and are compared with pure R134a refrigerant system.

The various parameters used for this experiment are detailed in the following:

$\mathrm{P}_{\mathrm{c}}$ defines condensing pressure;

$\mathrm{P}_{\mathrm{e}}$ defines evaporating pressure;

$\mathrm{T}_{1}=$ Outlet temperature evaporator $\left({ }^{\circ} \mathrm{C}\right)$;

$\mathrm{T}_{2}=$ Inlet temperature condenser $\left({ }^{\circ} \mathrm{C}\right)$;

$\mathrm{T}_{3}=$ Outlet temperature condenser $\left({ }^{\circ} \mathrm{C}\right)$;

$\mathrm{T}_{4}=$ Inlet temperature evaporator $\left({ }^{\circ} \mathrm{C}\right)$;

$\mathrm{T}_{5}=$ Evaporator water temperature $\left({ }^{\circ} \mathrm{C}\right)$;

$\mathrm{H}_{1}=$ Outlet temperature evaporator enthalpy $(\mathrm{kJ} / \mathrm{kg})$;

$\mathrm{H}_{2}=$ Inlet temperature condenser enthalpy $(\mathrm{kJ} / \mathrm{kg})$;

$\mathrm{H}_{3}=\mathrm{H}_{4}=$ Outlet temperature condenser enthalpy $(\mathrm{kJ} / \mathrm{kg})$;

$\mathrm{RE}=$ Refrigerant effect;

$\mathrm{COP}=$ Coefficient of performance.

Table 7 shows the enthalpy values of R134a from various experiments conducted.

Table 7: Available enthalpy values of R134a from various experiments [11].

\begin{tabular}{|c|c|c|c|}
\hline \multicolumn{4}{|c|}{ Available enthalpy values of R134a } \\
\hline $\mathrm{H}_{1}$ & $\mathrm{H}_{2}$ & $\mathrm{H}_{3}$ & $\mathrm{H}_{4}$ \\
\hline 256.40 & 380.30 & 445.33 & 256.40 \\
\hline
\end{tabular}

With reference to Table 7, the COP for R134a refrigerant is calculated as shown below:

$\mathrm{COP}=\left(\mathrm{H}_{2}-\mathrm{H}_{1}\right) /\left(\mathrm{H}_{3}-\mathrm{H}_{2}\right)=(380.30-256.40) /(445.33-380.30)=1.90 ;$

$\mathrm{RE}=\left(\mathrm{H}_{2}-\mathrm{H}_{1}\right)=(380.30-256.40)=124$.

Available observations from available experiments/research papers for the selected refrigerant-nanoparticles mixtures are tabulated in Tables 8-11. 
Table 8: $\mathrm{R} 134 \mathrm{a}-\mathrm{Al}_{2} \mathrm{O}_{3}$ observations [12].

\begin{tabular}{|c|c|c|c|c|c|}
\hline \multicolumn{5}{|c|}{ R134a- $-\mathbf{A l}_{2} \mathbf{O}_{3}$ mixture } \\
\hline Pressure (bar) & \multicolumn{5}{|c|}{ Temperature $\left({ }^{\circ} \mathbf{C}\right)$} \\
\hline $\mathrm{P}_{\mathrm{e}}$ & $\mathrm{P}_{\mathrm{c}}$ & $\mathrm{T}_{1}$ & $\mathrm{~T}_{2}$ & $\mathrm{~T}_{3}$ & $\mathrm{~T}_{4}$ \\
\hline 1.90 & 11 & 30 & 60 & 37.5 & 21 \\
\hline
\end{tabular}

From Table 8, the enthalpy values are obtained from $\mathrm{p}$-h chart of R134a:

$\mathrm{H}_{1}-\mathrm{H}_{2}$ undergoes isobaric evaporation;

$\mathrm{H}_{2}-\mathrm{H}_{3}$ undergoes isentropic compression;

$\mathrm{H}_{3}-\mathrm{H}_{4}$ undergoes isobaric condensation;

$\mathrm{H}_{4}-\mathrm{H}_{1}$ undergoes isentropic expansion.

Fig. 3, depicts the $\mathrm{PH}$ chart used for inferring the corresponding enthalpies as per Table 8 .

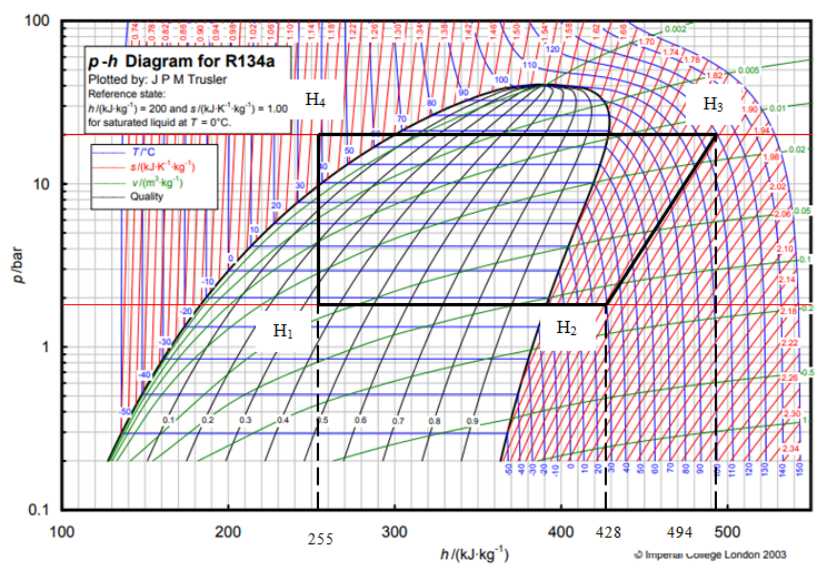

Figure 3: R134a-A12O3 p-h chart.

From Fig. 3:

$\mathrm{H}_{1}=\mathrm{H}_{4}=255, \mathrm{H}_{2}=428, \mathrm{H}_{3}=494$;

$\mathrm{COP}=\left(\mathrm{H}_{2}-\mathrm{H}_{1}\right) /\left(\mathrm{H}_{3}-\mathrm{H}_{2}\right)=(428-255) /(494-428)=173 / 66=2.62$;

$\mathrm{RE}=\left(\mathrm{H}_{2}-\mathrm{H}_{1}\right)=(428-255)=173$.

Table 9: $\mathrm{R} 134 \mathrm{a}-\mathrm{CuO}$ observations [12].

\begin{tabular}{|c|c|c|c|c|c|}
\hline \multicolumn{5}{|c|}{ R134a and CuO mixture } \\
\hline \multicolumn{4}{|c|}{ Pressure (bar) } & \multicolumn{4}{|c|}{ Temperature $\left({ }^{\circ} \mathbf{C}\right)$} \\
\hline $\mathrm{P}_{\mathrm{e}}$ & $\mathrm{P}_{\mathrm{c}}$ & $\mathrm{T}_{1}$ & $\mathrm{~T}_{2}$ & $\mathrm{~T}_{3}$ & $\mathrm{~T}_{4}$ \\
\hline 1.50 & 9 & 17 & 47 & 33 & 20 \\
\hline
\end{tabular}

Fig. 4 depicts the PH chart used for inferring the corresponding enthalpies as per Table 9. 


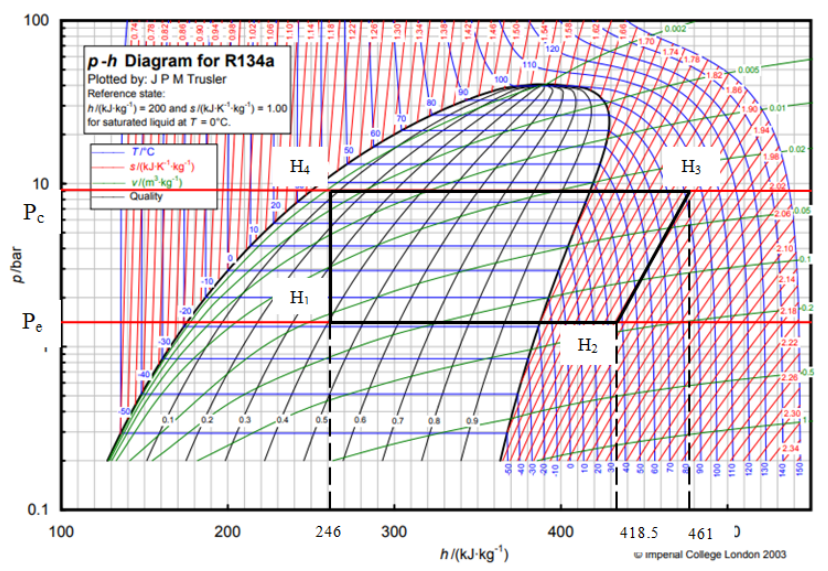

Figure 4: R134a - CuO p-h chart.

From Fig. 4:

$\mathrm{H}_{1}=\mathrm{H}_{4}=246, \mathrm{H}_{2}=418.50, \mathrm{H}_{3}=461$;

$\mathrm{COP}=\left(\mathrm{H}_{2}-\mathrm{H}_{1}\right) /\left(\mathrm{H}_{3}-\mathrm{H}_{2}\right)=(418.5-246) /(461-418.5)=172.5 / 42.5=4.06$;

$\mathrm{RE}=\left(\mathrm{H}_{2}-\mathrm{H}_{1}\right)=(418.5-246)=172.5$.

Table 10: $\mathrm{R} 134 \mathrm{a}-\mathrm{TiO}_{2}$ observations [13].

\begin{tabular}{|c|c|c|c|c|c|}
\hline \multicolumn{5}{|c|}{ R134a and $\mathrm{TiO}_{2}$ mixture } \\
\hline \multicolumn{2}{|c|}{ Pressure (bar) } & \multicolumn{4}{|c|}{ Temperature $\left({ }^{\circ} \mathbf{C}\right)$} \\
\hline $\mathrm{P}_{\mathrm{e}}$ & $\mathrm{P}_{\mathrm{c}}$ & $\mathrm{T}_{1}$ & $\mathrm{~T}_{2}$ & $\mathrm{~T}_{3}$ & $\mathrm{~T}_{4}$ \\
\hline 2 & 16 & 21 & 60 & 26 & 6 \\
\hline
\end{tabular}

Fig. 5 depicts the $\mathrm{PH}$ chart used for inferring the corresponding enthalpies as per Table 10.

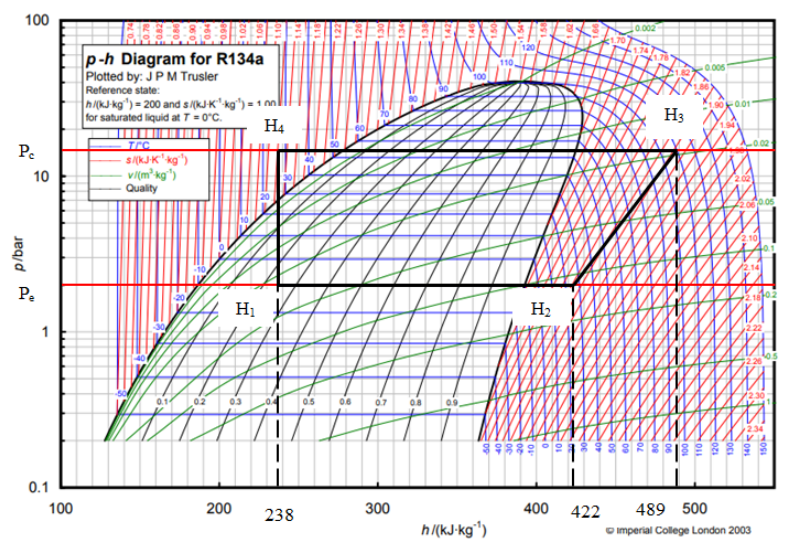

Figure 5: $\mathrm{R} 134 \mathrm{a}-\mathrm{TiO}_{2} \mathrm{p}-\mathrm{h}$ chart. 
From Fig. 5:

$\mathrm{H}_{1}=\mathrm{H}_{4}=238, \mathrm{H}_{2}=422, \mathrm{H}_{3}=489$;

$\mathrm{COP}=\left(\mathrm{H}_{2}-\mathrm{H}_{1}\right) /\left(\mathrm{H}_{3}-\mathrm{H}_{2}\right)=(422-238) /(489-422)=184 / 67=2.75$;

$\mathrm{RE}=\left(\mathrm{H}_{2}-\mathrm{H}_{1}\right)=(422-238)=184$.

Table 11: $\mathrm{R} 134 \mathrm{a}-\mathrm{ZnO}$ observations [12].

\begin{tabular}{|c|c|c|c|c|c|}
\hline \multicolumn{5}{|c|}{ R134a and ZnO mixture } \\
\hline \multicolumn{2}{|c|}{ Pressure (bar) } & \multicolumn{4}{|c|}{ Temperature $\left({ }^{\circ} \mathbf{C}\right)$} \\
\hline $\mathrm{P}_{\mathrm{e}}$ & $\mathrm{P}_{\mathrm{c}}$ & $\mathrm{T}_{1}$ & $\mathrm{~T}_{2}$ & $\mathrm{~T}_{3}$ & $\mathrm{~T}_{4}$ \\
\hline 1.85 & 12.5 & 23 & 59 & 30 & 19 \\
\hline
\end{tabular}

Fig. 6 depicts the $\mathrm{PH}$ chart to infer the corresponding enthalpies as per Table 11.

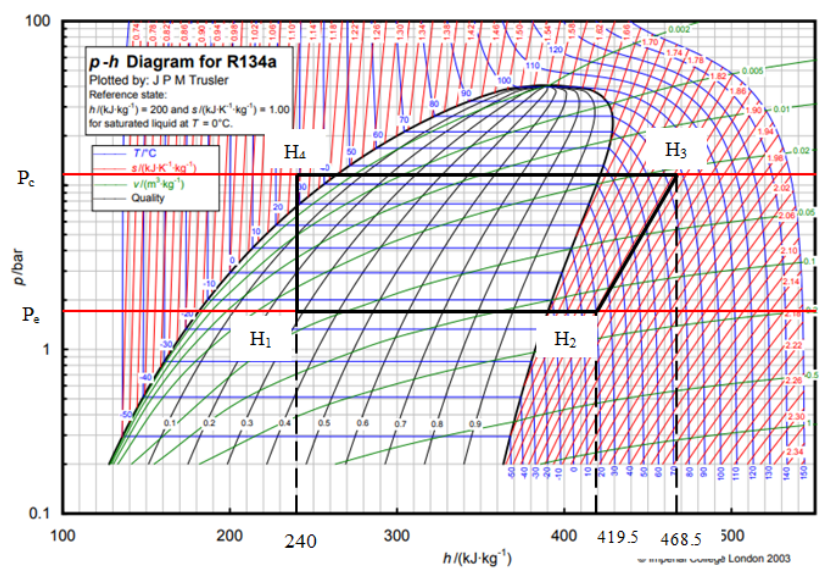

Figure 6: R134a - ZnO p-h chart.

From Fig. 6:

$\mathrm{H}_{1}=\mathrm{H}_{4}=240, \mathrm{H}_{2}=419.5, \mathrm{H}_{3}=468.5$;

$\mathrm{COP}=\left(\mathrm{H}_{2}-\mathrm{H}_{1}\right) /\left(\mathrm{H}_{3}-\mathrm{H}_{2}\right)=(419.5-240) /(468.5-419.5)=179.5 / 49=3.66$;

$\mathrm{RE}=\left(\mathrm{H}_{2}-\mathrm{H}_{1}\right)=(419.2-240)=179.5$.

\section{RESULTS AND CONCLUSION}

Table 12 shows the values of RE and COP for various mixtures of R134a and nanoparticles.

Table 12: Experimental results.

\begin{tabular}{|c|c|c|}
\hline $\begin{array}{c}\text { Mixture of R134a and } \\
\text { nanoparticles }\end{array}$ & Refrigeration effect (RE) & $\begin{array}{c}\text { Coefficient of } \\
\text { performance (COP) }\end{array}$ \\
\hline $\mathrm{R} 134 \mathrm{a}-\mathrm{Al}_{2} \mathrm{O}_{3}$ & 173 & 2.62 \\
\hline $\mathrm{R} 134 \mathrm{a}-\mathrm{CuO}$ & 172 & 4.06 \\
\hline $\mathrm{R} 134 \mathrm{a}-\mathrm{TiO}_{2}$ & 184 & 2.74 \\
\hline $\mathrm{R} 134 \mathrm{a}-\mathrm{ZnO}$ & 179.5 & 3.66 \\
\hline
\end{tabular}


The RE and COP are calculated for R134a mixed with different nanoparticles. From the experimental calculations, system performance is high for $\mathrm{R} 134 \mathrm{a}-\mathrm{CuO}$ refrigerant with COP of 4.06 compared to other mixtures. The COP for pure R134a is 1.90 . COP values for different mixtures tabulated in Table 12 are higher than pure R134a.From the results COP of refrigeration system with added nano additives in R134a refrigerant is higher than that of systems running with pure R134a refrigerant (without nanoparticles).

Low values of COP lead to increase in compressor power of the system and high values of COP lead to energy savings. Here the energy of the refrigeration systems is reduced due to the addition of nanoparticles in refrigerant fluid. Around $38 \%$ increase in COP was recorded in this study. CuO nanoparticles show high value of COP when blended with R134a compared to other nanoparticles. COP of the refrigeration systems vary with the type of refrigerants used in the system. COP of nanoparticles blended R134a refrigerant is different compared to nanoparticles blended with other refrigerants (R600, R152a, R290).

Hence it can be concluded that, dispersion of nano additives, leads to maximising the thermal conductivity, heat transfer coefficient and other heat transfer characteristics which further leads to the enhancement of refrigeration systems effectively and augment the energy savings.

\section{REFERENCES}

[1] Shu, S., Hongying, Z., Keming, C. \& Yizhao, W., The full flowpath analysis of a hypersonic vehicle. Chinese Journal of Aeronautics, 20(5), pp. 385-393, 2007.

[2] Mahapatra, D. \& Jagadeesh, G., Shock tunnel studies on cowl/ramp shock interactions in a generic scramjet inlet. Proceedings of the Institution of Mechanical Engineers, Part G: Journal of Aerospace Engineering, 222(8), pp. 1183-1191, 2008.

[3] Araner, Vapor compression refrigeration cycle. www.araner.com/blog/vaporcompression-refrigeration-cycle/\%20(VCR.

[4] Price, S.H., Vapor Compression refrigeration. Refrigeration-vapor compression, 2007. www.mesubjects.net/vapor-compression-refrigeration-cycle/.

[5] Manimaran, R., Palaniradja, K., Natarajan, A., Sendhilnathan, S. \& Hussain, J., Preparation and characterization of copper oxide nanofluid for heat transfer applications. Applied Nanoscience, 4(2), 2013.

[6] Eastman, J.A., Choi, S.U.S., Li, S., Yu, W. \& Thompson, L.J., Anomalously increased effective thermal conductivity of ethylene glycol-based nanofluids containing copper nanoparticles. Applied Physics Letters, 78(6), 2001.

[7] Taghizadeh-Tabari, Z., Zeinali Heris, S., Moradi, M. \& Kahani, M., The study on application of $\mathrm{TiO}_{2} /$ water nanofluid in plate heat exchanger of milk pasteurization industries. Renewable and Sustainable Energy Reviews, 58, pp. 1318-1326, 2016.

[8] Islam, M.M., Ahmad, S., Rahman, S., Alam, M.K. \& Kamyar, A., Thermal performance analysis of $\mathrm{AL}_{2} \mathrm{O}_{3} / \mathrm{R}-134$ a nanorefrigerant. International Journal of Heat and Mass Transfer, 85, pp. 1034-1040, 2015.

[9] Yu, W. \& Xie, H., A review on nanofluids: Preparation, stability mechanisms, and applications. Journal of Nanomaterials, 2012, 2011.

[10] Chegg, The thermodynamic state. https://www.chegg.com/.

[11] Özkan, D., Agra, Ö. \& Çetin, Ö., A comparison between refrigerants used in air conditioning. Proceedings of Clima 2007 WellBeing Indoors.

[12] Dongare, V.K., Kadam, J., Samel, A., Pawar, R. \& Sarvankar, S., Enhancement of vapor compression refrigeration system using nanofluids. International Research Journal of Engineering and Technology (IRJET), 4(4), pp. 2218-2225, 2017. 
294 Sustainable Development and Planning XI

[13] MatWeb, Titanium dioxide, $\mathrm{TiO}_{2}$, anatase. www.matweb.com/search/Data Sheet.aspx?MatGUID=71d316acbb8d46478520b98a1255a845\&ckck=1.

[14] Ajayi, O.O., Ibia, D.E., Ogbonnaya, M., Attabo, A. \& Michael, A., CFD analysis of nanorefrigerant through adiabatic capillary tube of vapor compresion refrigeration system. International Conference on Sustainable Materials Processing and Manufacturing, 23-25 Jan., Kruger National Park, 2017.

[15] Ghorbani, B., Akhavan-Behabadi, M.A., Ebrahimi, S. \& Vijayaraghavan, K., Experimental investigation of condensation heat transfer of $\mathrm{R} 600 \mathrm{a} / \mathrm{POE} / \mathrm{CuO}$ nanorefrigerant in flattened tubes. International Communications in Heat and Mass Transfer, 88, pp. 236-244, 2017. 